\title{
DIREITO HUMANO À ALIMENTAÇÃO ADEQUADA: UMA VISÃO HOLÍSTICA ${ }^{1}$
}

\author{
Maria Vitória Fontolan ${ }^{2}$ \\ Romilda de Souza Lima ${ }^{3}$
}

\begin{abstract}
Resumo: Este artigo traz reflexões gerais acerca do Direito Humano à Alimentação Adequada - DHAA, em especial quanto a sua abrangência e complexidade. Para isso, com o objetivo de compreender o DHAA, foram abordadas cinco dimensões: a) dimensão fisiológica/nutricional; b) dimensão cultural; c) dimensão gênero; d) dimensão informação; e) dimensão ambiental. Tais dimensões são exemplificativas e demonstram as relações do DHAA com outros direitos humanos e sua importância para uma vida digna.
\end{abstract}

Palavras-chave: Direito humano à Alimentação Adequada. Cultura. Gênero. Direito à Informação. Sustentabilidade.

\section{HUMAN RIGHT TO ADEQUATE FOOD: A HOLISTIC PERSPECTIVE}

\begin{abstract}
The aim of this article is to reflect about the Human Right to Adequate Food, specially about its amplitude and complexity. Therefore, in order to comprehend the Human Right to Adequate Food, five dimensions were contemplated: a) physiologic/nutritional dimension; b) cultural dimension; c) gender dimension; d) information dimension; e) environmental dimension. These dimensions are examples to show the relation that Human Right to Adequate Food has with another human rights and its importance for a dignity life.
\end{abstract}

Keywords: Human Right to Adequate Food. Culture. Gender. Right to information. Sustainability.

\section{Introdução}

O conceito do Direito Humano à Alimentação Adequada - DHAA está em constante construção. Corrêa e Oliveira (2019, p. 37) entendem que ele deve ser compreendido como "uma rede conceitual e uma relação dinâmica de interação de novos sentidos e categorias que emergem das lutas sociais, de modo a viabilizar uma permanente reconstrução do significado do direito humano a alimentação adequada".

De acordo com Valente (2002, p. 92):

O conceito do direito humano à alimentação e nutrição no Brasil é holístico e incorpora os componentes nutricionais, culturais, fisiológicos, familiares, comunitários, espirituais e religiosos do ato de alimentar-se e alimentar, refletindo claramente a indivisibilidade dos direitos humanos.

\footnotetext{
${ }^{1}$ Este artigo corresponde a uma parte de um dos capítulos da dissertação de mestrado da primeira autora, em fase de conclusão, com recurso de bolsa de pós-graduação pela Coordenação de Aperfeiçoamento de Pessoal de Nível Superior (CAPES).

2 Graduada em Direito. Mestranda em Desenvolvimento Rural Sustentável pelo Programa de Pós-graduação em Desenvolvimento Rural Sustentável - UNIOESTE. Integra o Grupo de Pesquisa em Segurança Alimentar (Gepsa). Email: mvfontolan@gmail.com Orcid: https://orcid.org/0000-0002-8057-6442

${ }^{3}$ Professora Adjunta na Universidade Estadual do Oeste do Paraná - UNIOESTE, campus de Francisco Beltrão, Departamento de Nutrição. Professora Permanente no Programa de Pós-Graduação em Desenvolvimento Rural Sustentável, da UNIOESTE, campus de Marechal Cândido Rondon. Integra a Rede Nacional de Pesquisa em Segurança Alimentar e Nutricional e o Grupo de Pesquisa em Segurança Alimentar (Gepsa) - UNIOESTE. Email: romislima2@gmail.com Orcid: https://orcid.org/0000-0002-0968-0044
} 
Em 2002, Jean Ziegler, relator da ONU para o DHAA, definiu o DHAA como:

O direito à alimentação adequada é um direito humano inerente a todas as pessoas de ter acesso regular, permanente e irrestrito, quer diretamente ou por meio de aquisições financeiras a alimentos seguros e saudáveis, em quantidade e qualidade adequadas e suficientes, correspondentes às tradições culturais do seu povo e que garanta uma vida livre do medo, digna e plena nas dimensões física e mental, individual e coletiva (BURITY et al., 2010, p. 15).

De acordo com Valéria Burity et al (2010), o DHAA possui duas dimensões indivisíveis: o direito de estar livre da fome e da má nutrição e o direito à uma alimentação adequada. Siqueira (2013) entende o DHAA como um direito pluridimensional.

Por isso, a importância de entender todas as possibilidades que ele envolve. Estudar o DHAA é dar visibilidade a tudo o que ele significa para a sociedade, bem como permitir que ele possa ser realizado de forma eficaz, corroborando, consequentemente, para a efetivação de diversos outros direitos e vice-versa.

Os direitos humanos fundamentais são indivisíveis e interdependentes, ou seja, um direito não tem plena eficácia sem que outros também sejam realizados (GUERRA, 2020). Assim, será possível perceber que as temáticas abordadas ao longo deste artigo, direta ou indiretamente, abrangem diversos outros direitos humanos, como o direito à saúde, ao meio ambiente equilibrado, à igualdade, à valorização da cultura, e principalmente à vida (digna) ${ }^{4}$.

Nesse contexto, não temos, com este trabalho, a pretensão de exaurir a densidade material do DHAA, nem mesmo limitá-lo a uma categorização. Ao contrário, o intuito é enfatizar a riqueza, abrangência e importância de todas as categorias presentes nesse direito, bem como demonstrar como cada uma das dimensões, aqui apresentadas, estão em constante diálogo. Vivemos em uma sociedade plural, diversa, em constante mutação, e é nesse contexto em que o DHAA se insere.

Entendemos que ao mesmo tempo em que isso demonstra a riqueza e complexidade dos direitos humanos, e em especial do DHAA, pode implicar, sistematicamente, como um obstáculo a sua efetivação. Todavia, nosso objetivo aqui, não é sermos pessimistas quanto às "dificuldades" de efetivação, mas sim trazer a centralidade do DHAA para a garantia de uma vida digna.

Assim, com o objetivo de elucidar o conteúdo material do DHAA, de uma forma geral, este artigo contempla algumas de suas dimensões, sendo elas: a) dimensão fisiológica/nutricional; b) dimensão cultural; c) dimensão gênero; d) dimensão informação; e) dimensão ambiental. Para isso, a estrutura metodológica do artigo caracteriza-se como uma revisão de literatura narrativa,

\footnotetext{
${ }^{4}$ São, ainda, direitos humanos relacionados ao DHAA: direito ao trabalho, à segurança social, à proibição do trabalho infantil (BESSA, 2019); direito à propriedade, à educação, à informação.
} 
por meio de um levantamento bibliográfico e documental a partir de bancos de dados disponíveis na internet (Portal de Periódicos CAPES/MEC e Google Acadêmico), bibliografias, legislações nacionais, tratados internacionais e documentos de sites oficiais.

\section{Apresentando as dimensões do DHAA:}

\section{Dimensão fisiológica/nutricional (o direito à vida livre da fome e da má-nutrição)}

De acordo com a FAO et al. (2020) aproximadamente 690 milhões de pessoas passam fome no mundo. Em 2019, cerca de 750 milhões de pessoas estavam expostas a níveis severos de insegurança alimentar e nutricional (IAN). Ainda, somando-se o número de pessoas em situação de insegurança alimentar e nutricional moderada e severa, estima-se que 2 bilhões de pessoas no mundo não tiveram acesso regular a alimentos seguros, nutritivos e suficientes em 2019.

O direito de estar livre da fome é a dimensão do DHAA de realização imediata. A fome pode ser aguda ou crônica; esta "ocorre quando a alimentação diária, habitual, não propicia ao indivíduo energia suficiente para a manutenção do seu organismo e para o desempenho de suas atividades cotidianas" (MONTEIRO, 2003, p. 8); já aquela se traduz na necessidade imediata de se alimentar.

Valente (2003) entende que a fome deve ser vista como um fenômeno amplo e subjetivo:

O conceito de fome, no Brasil, utilizado por diferentes setores da população, abarca desde aquela sensação fisiológica ligada à vontade de comer, conhecida de todos nós, até as formas mais brutais de violentação do ser humano, ligadas à pobreza e à exclusão social. Ver os filhos passarem fome é passar fome. Comer lixo é passar fome. Comer o resto do prato dos outros é passar fome. Passar dias sem comer é passar fome. Comer uma vez por dia é passar fome. Ter que se humilhar para receber uma cesta básica é passar fome. Trocar a dignidade por comida é passar fome. Ter medo de passar fome é estar cativo da fome. Estar desnutrido também é passar fome, mesmo que a causa principal não seja falta de alimento (VALENTE, 2003, p. 56, 57).

Josué de Castro, já muito antes, na década de 1930, alertou e denunciou sobre os flagelos da fome e desnutrição no Brasil, inicialmente a partir de suas experiências como médico em Recife. Por meio de realização de inquéritos alimentares, e sobre condições de vida da classe trabalhadora, apontou dados e análises fundamentais para desnaturalizar a fome e a desnutrição, apontando como causa o histórico de desigualdades sociais e econômicas no País.

Para além das desigualdades socioeconômicas, mas também associadas, fome e desnutrição atingem populações de regiões de conflitos de natureza diversa, por exemplo: geopolíticos e religiosos, o que leva a imensas crises humanitárias, como apontado por José 
Graziano da Silva, ex- Diretor Geral da FAO, em recente artigo Graziano da Silva (2020) afirma que "não podemos aceitar conviver com a fome e as diferentes formas de má nutrição que decorrem da pobreza, da miséria e da má distribuição da renda do mundo em que vivemos" (p. 3).

Ziegler (2012) aponta que os grupos mais vulneráveis a fome são os pobres rurais, os pobres urbanos e as vítimas de catástrofes.

Segundo relatório da FAO et al. (2020) o principal motivo pelo qual milhões de pessoas ainda passam fome ou estão em estado desnutrição e insegurança alimentar no mundo é pelo motivo de elas não terem condições de custear dietas saudáveis. De acordo com o relatório, dietas saudáveis custam, aproximadamente, cinco vezes mais do que dietas que apenas atendem às necessidades calóricas diárias.

It is unacceptable that, in a world that produces enough food to feed its entire population, more than 1.5 billion people cannot afford a diet that meets the required levels of essential nutrients and over 3 billion people cannot even afford the cheapest healthy diet. People without access to healthy diets live in all regions of the world; thus, we are facing a global problem that affects us all (FAO et al, 2020, p. 09).

No Brasil, os dados também são preocupantes, de acordo com a FAO et al. (2020), entre 2017 e 2019 a média de pessoas em situação de insegurança alimentar e nutricional moderada ou severa foi de 43,1 milhões. E, como apontado Daufenback; Coelho; Bógus (2021), é muito preocupante o agravamento da IAN durante a pandemia pela Covid-19 e alertam que a condição de insegurança alimentar e nutricional e a fome ocorrem ao mesmo tempo em que há também registros de aumento de obesidade e sobrepeso nas últimas décadas.

Burity et al (2010) entendem que a principal causa da desnutrição no país não está relacionada a disponibilidade de alimentos, mas sim a desigualdade de acesso a eles. Nesse mesmo sentido, Valente (2002, p. 106) entende que:

A fome não acontece porque deu um apagão no sol para alguns, mas sim porque a sociedade criou cercas arbitrárias que definem quem tem direito à terra, quem tem direito à água, quem tem direito à emprego, quem tem direito à educação e informação, entre outras tantas coisas. Gera-se a exclusão e a fome. Assim, gerase falta de controle sobre a própria vida, sobre a alimentação e sobre a saúde. Ou seja, assim se limita o acesso dos seres humanos à riqueza científica, cultural, material e espiritual produzida socialmente pela humanidade e acumula de forma privada pelas elites e grupos políticos e econômicos dominantes.

Nas palavras de Maniglia (2009, p. 205) “[...] a fome no mundo não é a escassez de comida, mas a escassez de democracia".

Ziegler (2012) compara a fome ao crime organizado, pois, segundo ele: 
A influência das sociedades transcontinentais privadas da agroindústria nas estratégias das organizações internacionais - como, ademais, da quase totalidade dos governos ocidentais - é frequentemente decisiva. Essas sociedades atuam como inimigos jurados do direito à alimentação. Sua argumentação é a seguinte: a fome constitui, de fato, uma tragédia escandalosa; ela se deve à produtividade insuficiente da agricultura mundial - os bens disponíveis não atendem às necessidades existentes -; assim, para combater a fome, é preciso incrementar a produtividade, o que só é possível sob duas condições: primeira, uma industrialização levada ao limite, mobilizando um máximo de capital e as tecnologias mais avançadas (sementes transgênicas, pesticidas eficazes etc.) e eliminando, como corolário, a miríade de pequenas explorações reputadas "improdutivas" da agricultura familiar e de víveres; segunda, a liberalização tão completa quanto possível do mercado agrícola mundial (ZIEGLER, 2012, p. 122).

A fome impede o ser humano de se desenvolver, de viver, de ser. Ela nega sua humanidade. São cruéis os seres humanos que a negam, permitindo que projetos econômicos se sobreponham à vida.

Além de uma vida livre da fome, o DHAA visa que seja igualmente livre da má-nutrição. Nesse sentido, além do direito à alimentos em quantidade suficiente, o DHAA pressupões a qualidade e a segurança desses alimentos.

A Lei Orgânica de Segurança Alimentar e Nutricional - Losan (Lei n 11.346/2006) estabelece que:

Art. $3^{\circ}$ A segurança alimentar e nutricional consiste na realização do direito de todos ao acesso regular e permanente a alimentos de qualidade, em quantidade suficiente, sem comprometer o acesso a outras necessidades essenciais, tendo como base práticas alimentares promotoras de saúde que respeitem a diversidade cultural e que sejam ambiental, cultural, econômica e socialmente sustentáveis (grifo nosso).

Alimentos seguros e saudáveis são um direito desde a vida intrauterina. Assim, o DHAA também engloba o direito da mãe a um pré-natal e alimentação adequada e posteriormente o direito ao aleitamento materno ${ }^{5}$ - que, para Burity et al (2010, p. 158) "pode ser considerado a primeira expressão do DHAA do indivíduo ao nascer".

O mundo convive com diversas formas de má nutrição. Ao mesmo tempo em que existem aqueles que são privados de se alimentar, há aqueles que têm acesso a alimentos sem variedade ou qualidade nutricional.

\footnotetext{
${ }^{5}$ A Convenção sobre a Eliminação de Todas as Formas de Discriminação contra a Mulher de 1979 - internalizada no Brasil em 1984 - prevê no artigo 12. 2 que: [...] os Estados-Partes garantirão à mulher assistência apropriada em relação à gravidez, ao parto e ao período posterior ao parto, proporcionando assistência gratuita quando assim for necessário, e lhe assegurarão uma nutrição adequada durante a gravidez e a lactância” (BRASIL, 1984).
} 
Segundo Valente (2003, p. 57) a má nutrição “[...] engloba tanto a desnutrição decorrente de carências nutricionais (energia, proteína e micronutrientes) como os quadros causados por uma ingestão excessiva ou desbalanceada de nutrientes, tais como a obesidade, dislipidemias e outras doenças crônicas".

Muitas pessoas acabam tendo como grande parte de suas dietas - seja por falta de informação ou por falta de acesso físico ou financeiro - alimentos ultraprocessados, transgênicos, contaminados com agrotóxicos ou/e de qualidade sanitária inadequada (BURITY et al, 2010).

Em 2014, o Ministério da Saúde, divulgou o Guia Alimentar para a População Brasileira (BRASIL, 2014), o qual, dentre diversas recomendações, enfatiza que uma alimentação adequada e saudável tem como base alimentos in natura e minimante processado, limita o consumo de alimentos processados e evita alimentos ultraprocessados. Além disso, dá preferência a alimentos da estação, cultivados localmente, de preferência orgânicos e de base agroecológica.

A disponibilidade e o acesso a alimentos saudáveis são fatores determinantes para uma vida livre da má nutrição. Segundo relatório divulgado pela FAO et al (2020), mais de 3 (três) bilhões de pessoas no mundo não tem acesso a dietas saudáveis.

Ainda, o relatório explica que existem fortes evidências de que os altos custos de opções alimentares saudáveis, contrapondo a custos mais baixos de alimentos menos nutritivos, contribuem para o excesso de peso e obesidade (FAO et al, 2020).

Em 2018, no Brasil, 12 de 21 capitais apresentavam desertos alimentares em suas periferias (CAISAN, 2018). O termo "deserto alimentar" é utilizado para designar localidades onde a oferta de alimentos saudáveis é limitada, ou seja, onde o acesso físico a alimentos in natura ou minimamente processados é restrito (IDEC, 2019).

O termo "pântanos alimentares" também tem se difundido para caracterizar locais onde há a venda de alimentos altamente calóricos e com poucos nutrientes, como redes de fast food ou lojas de conveniência (IDEC, 2019).

Assim, muitos acabam limitando suas dietas àqueles alimentos que contêm altos níveis de sódio, açúcar e gordura.

Quanto à segurança dos alimentos, cabe destacar que o crescente uso de agrotóxicos e sementes transgênicas traz diversas preocupações quanto à segurança alimentar e nutricional dos que os consomem, pois os resíduos de agrotóxicos nos alimentos, tanto in natura quanto processados, podem trazer agravos à saúde daqueles que os consomem. Segundo o Instituto Nacional de Câncer José Alencar Gomes da Silva - INCA (2015, p. 2,3):

O modelo de cultivo com o intensivo uso de agrotóxicos gera grandes malefícios, como poluição ambiental e intoxicação de trabalhadores e da população em geral. As intoxicações agudas por agrotóxicos são as mais conhecidas e afetam, 
principalmente, as pessoas expostas em seu ambiente de trabalho (exposição ocupacional). São caracterizadas por efeitos como irritação da pele e olhos, coceira, cólicas, vômitos, diarreias, espasmos, dificuldades respiratórias, convulsões e morte. Já as intoxicações crônicas podem afetar toda a população, pois são decorrentes da exposição múltipla aos agrotóxicos, isto é, da presença de resíduos de agrotóxicos em alimentos e no ambiente, geralmente em doses baixas. Os efeitos adversos decorrentes da exposição crônica aos agrotóxicos podem aparecer muito tempo após a exposição, dificultando a correlação com o agente. Dentre os efeitos associados à exposição crônica a ingredientes ativos de agrotóxicos podem ser citados infertilidade, impotência, abortos, malformações, neurotoxicidade, desregulação hormonal, efeitos sobre o sistema imunológico e câncer.

Segundo documento do Conselho Nacional de Segurança Alimentar (CONSEA, 2012) extinto desde 2019 - o uso de agrotóxicos no país é uma das mais graves e persistentes violações ao DHAA e se contradiz com o artigo $3^{\circ}$ da Losan. Pois, ele impede o acesso da população à um alimento limpo e saudável e gera diversas doenças.

Por fim, cabe ressaltar que direito à água também se encontra inserido no universo do DHAA (ZIEGLER, 2012). O acesso à água potável para o consumo, higienização de alimentos e para a agricultura - é fundamental, no entanto, tem sido desrespeitado tanto em acesso, quanto em qualidade a muitas parcelas da população, sobretudo as das camadas mais pobres e de regiões periféricas ${ }^{6}$. Um dos exemplos foi o recente caso da água poluída que chegou às torneiras das casas da população do Rio de Janeiro, amplamente divulgado pela mídia e debatido por pesquisadores. ${ }^{7}$

\section{Dimensão Gênero}

O histórico de restrições e violações de direitos e garantias fundamentais das mulheres se perpetua até hoje nas mais diversas esferas da sociedade. No contexto brasileiro, por muito tempo a mulher foi não foi vista, juridicamente, em situação de igualdade para com os homens, inclusive quanto a sua capacidade jurídica. Apenas com o advento da Constituição Federal de 1988 é que foi reconhecida a igualdade formal entre homens e mulheres (GUERRA, 2020).

Assim, embora juridicamente as mulheres estejam em situação de igualdade com homens, na prática a desigualdade, a violência e a discriminação contra mulheres são problemas estruturais que as impedem de usufruir uma vida digna. Educação, trabalho, participação, segurança social, salários, direitos sexuais e reprodutivos, divisão das tarefas domésticas e cuidado de filhos são algumas das diversas áreas nas quais as mulheres são submetidas a situações de injustiça.

\footnotetext{
${ }^{6}$ Para ver mais sobre isso, acessar: file:///C:/Users/Usuario/Downloads/Dialnet-DireitoHumanoAAguaEBioetica7207115.pdf

7 https://g1.globo.com/rj/rio-de-janeiro/noticia/2020/01/07/infectologista-pede-que-moradores-evitem-o-consumo-econtato-com-agua-turva-da-cedae-no-rio.ghtml
} 
No âmbito rural, esse contexto se replica de forma acentuada. Embora o trabalho das mulheres seja árduo, ele é pouco reconhecido e, em muitos casos, não é remunerado. Desigualdades no acesso à propriedade e recursos para produzir e na tomada de decisões fazem parte da realidade de muitas mulheres (SILIPRANDI, 2013).

Segundo relatório do relator especial para o Direito Humano à Alimentação da ONU Olivier De Schutter (2012) as diversas formas de discriminação contra as mulheres e meninas afetam diretamente seu direito à alimentação. Todas estão inter-relacionadas, de modo a formar ciclo de discriminação:

Figura 1 - Ciclo de discriminação

\section{The cycle of discrimination}

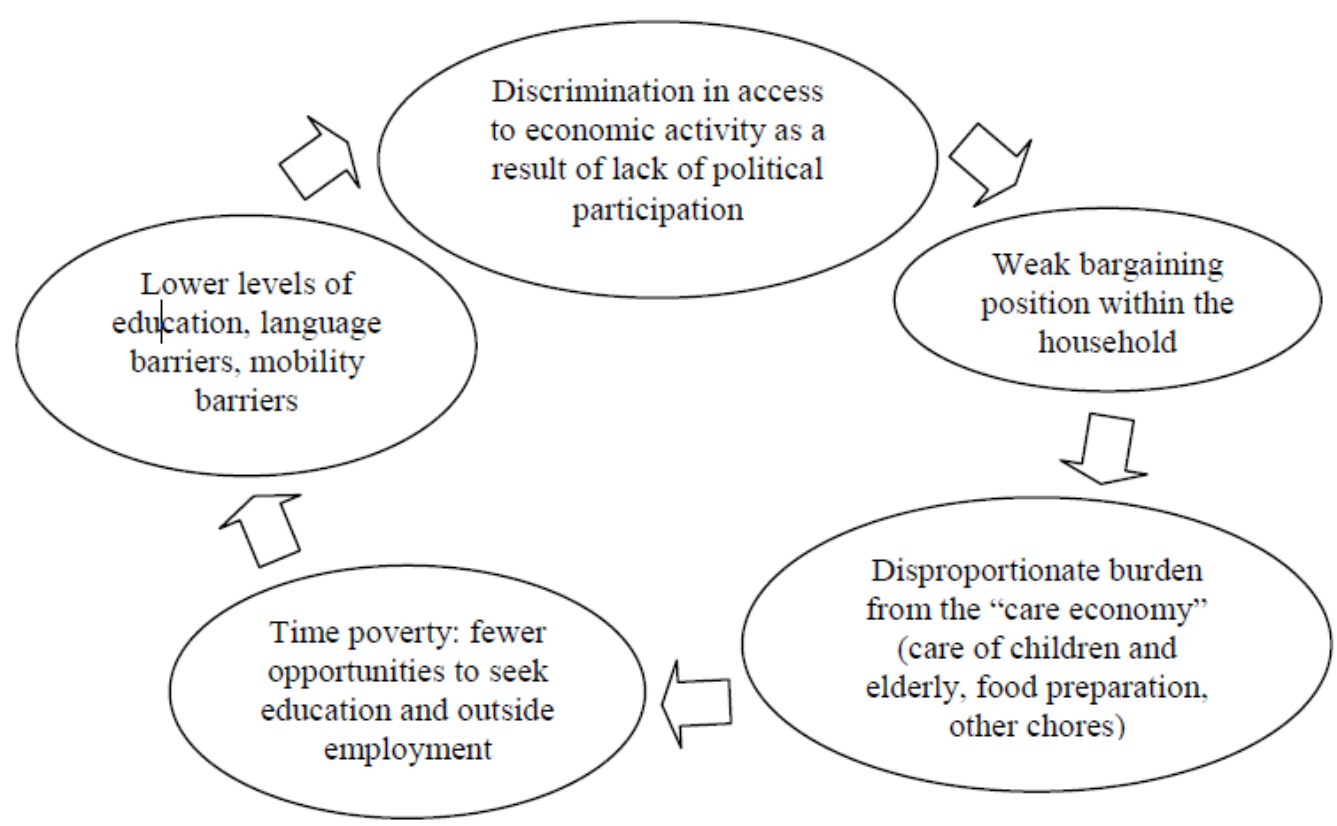

Fonte: (DE SCHUTTER, 2012, p. 4).

A invisibilidade de tarefas "designadas a mulheres", somada à discriminação de gênero, rouba delas oportunidades relacionadas a trabalhos remunerados, educação, participação na sociedade, entre outros. Desse modo, pode-se afirmar que a discriminação por gênero está diretamente relacionada à insegurança alimentar e nutricional. De acordo com a FAO et al (2020) a IAN prevalece em mulheres; a organização ressalta que mesmo quando elas têm os mesmos níveis de educação e vivem em áreas similares as de homens, seu acesso à alimentação é mais difícil. 
No Brasil, segundo a Pesquisa de Orçamentos Familiares 2017-2018 (IBGE, 2020), o sexo da pessoa de referência do domicílio está diretamente relacionado ao seu acesso a alimentos. Em domicílios em situação de segurança alimentar, 61,4\% tem homens como referência e, apenas, 38,6\% possuem mulheres como referência. Já em domicílios em situação de insegurança alimentar e nutricional, $51,9 \%$ tem a mulher como pessoa de referência.

Valente (2019, p. 3-4) explica esse fenômeno:

A má nutrição de mulheres, o baixo peso de recém-nascidos, a má nutrição infantil e o nanismo nutricional de crianças pequenas, bem como suas graves consequências na vida adulta, são, em grande medida, devidos ao fato de mulheres serem negadas as oportunidades de controlar suas vidas e corpos, de ser bem-alimentadas, de estudar, de definir quando e com quem querem se relacionar sexualmente, formar relações afetivas e procriar. Uma menina forcada a engravidar antes de se tornar fisiologicamente madura (em média, três anos após a menarca são necessários) ainda está crescendo, e o feto vai competir com ela por nutrientes. Isso afetara negativamente o status nutricional tanto da mãe como do feto. A violência contra meninas e mulheres, através de infanticídio, práticas discriminatórias de alimentação, casamento infantil, gravidez de adolescentes, estupro e normas que violam a autonomia de mulheres de decidir sobre sua vida e corpo influenciam não apenas o direito de mulheres e meninas a alimentação e nutrição, mas também o direito de seus filhos.

Bellows e Lemke (2016) elencam duas desconexões estruturais que impedem a realização do DHAA para as mulheres e meninas, bem como para todos: a primeira seria o afastamento entre os direitos das mulheres e o DHAA; a segunda seria o afastamento entre a produção de alimentos da nutrição, pois, dietas adequadas e alimentos justos, sustentáveis e culturalmente adequados incorporam os conceitos de Segurança Alimentar e Nutricional - SAN e DHAA. Segundo as autoras, a desconexão entre território e tradição, produção de alimentos e nutrição fortalece a ideia - equivocada e mal-intencionada - de que apenas mercados globais com tecnologias avançadas seriam capazes de resolver a insegurança alimentar e nutricional.

Oliver De Schutter (2012) defende que o empoderamento feminino deve estar na centralidade das estratégias de segurança alimentar, tanto para garantir o direito à alimentação das mulheres, quanto por ser a medida economicamente mais efetiva para reduzir a fome e má-nutrição de todos.

Bellows e Lemke (2016, p. 18) entendem que:

The evolution of the human right to adequate food and nutrition for all depends on the realisation of the full scope of women's (as well as men's) political and economic rights, as well as on empowered, gender-balanced and democratically organised communities and States that strive for self-determination and equity in more holistic and localised food and nutrition economies. 
Nesse mesmo sentido, Valente (2019, p. 3) afirma que "a realização plena dos direitos humanos das mulheres é central para a realização completa do direito à alimentação e nutrição adequadas para todos e todas".

Assim, não há como dissociar as diversas formas de má nutrição das mulheres da insegurança alimentar e nutricional de suas famílias. Pesquisas feitas por Pratley (2016), Bold et al (2013), demonstram que empoderamento feminino e a garantia da segurança alimentar e nutricional de mulheres estão diretamente associados à melhora da nutrição infantil e de suas próprias famílias.

Nesse sentido, as Diretrizes Voluntárias em apoio à realização progressiva do Direito Humano à Alimentação Adequada no Contexto da Segurança Alimentar Nacional, adotadas na $127^{\text {a }}$ Sessão do Conselho da FAO em novembro de 2004 em diversos pontos trazem a questão da equidade e necessidade de um olhar especial para as mulheres e meninas ${ }^{8}$ :

2.5 Os Estados deveriam colocar em prática políticas económicas, agrícolas, pesqueiras, florestais, de uso da terra e, quando apropriado, de reforma agrária acertadas, inclusivas e não-discriminatórias, que permitirão aos agricultores, pescadores, silvicultores e outros produtores de alimentos, em particular às mulheres, obter um rendimento justo do seu trabalho, capital e gestão, e deveriam estimular a conservação e o ordenamento sustentável dos recursos naturais, inclusive em zonas marginais.

3.8 Ao elaborarem estas estratégias, estimula-se os Estados a consultarem organizações da sociedade civil e outras partes interessadas fundamentais nos planos nacional e regional, incluindo as associações de agricultores que praticam uma agricultura tradicional em pequena escala, o sector privado, e associações de mulheres e de jovens, com vista a promover a sua participação ativa em todos os aspetos das estratégias de produção agrícola e alimentar.

3.9 Estas estratégias deveriam ser transparentes; inclusivas e amplas; transversais ao conjunto das políticas, programas e projetos nacionais; levar em consideração as necessidades especiais das meninas e das mulheres; combinar objetivos de curto e longo prazo; ser preparadas e aplicadas de forma participativa e com a obrigação de prestar contas.

7.4 Os Estados deveriam considerar a possibilidade de reforçar as suas políticas e leis internas a fim de permitir às mulheres chefes de família o acesso a projetos e programas relativos à redução da pobreza e à segurança nutricional.

10.8 Os Estados deveriam adotar medidas para erradicar quaisquer formas de práticas discriminatórias, especialmente a discriminação por motivos de género, com o objetivo de alcançar níveis adequados de nutrição dentro do lar.

10.10 Os Estados, tendo presente os valores culturais dos hábitos dietéticos e alimentares nas diferentes culturas, deveriam estabelecer métodos para promover a inocuidade dos alimentos e uma ingestão nutritiva positiva, incluindo uma repartição justa dos alimentos no seio das comunidades e dos lares, com especial ênfase nas necessidades e nos direitos das meninas e dos meninos, assim como das mulheres grávidas e das mães lactantes, em todas as culturas.

\footnotetext{
8 Para acesso às Diretrizes Voluntárias em apoio à realização progressiva do Direito Humano à Alimentação Adequada, na íntegra, acesse: http://www.fao.org/3/y7937pt/Y7937PT.pdf.
} 
17.5 Os Estados deveriam, em particular, monitorar a situação relativa à segurança alimentar dos grupos vulneráveis, especialmente as mulheres, as crianças e os idosos, assim como a sua situação nutricional, em particular as carências de micronutrientes (FAO, 2015, grifo nosso).

A Recomendação Geral no 24 para o artigo 12 da Convenção sobre a Eliminação de Todas as Formas de Discriminação contra a Mulher, relaciona o direito à saúde da mulher ao direito ao bem-estar nutricional:

7. O Comité nota que a plena concretização do direito das mulheres à saúde só pode ser alcançada quando os Estados Partes cumprirem a sua obrigação de respeitar, proteger e promover o direito humano fundamental das mulheres ao bem-estar nutricional ao longo do seu ciclo de vida, através de um fornecimento alimentar que seja seguro, nutritivo e ajustado às condições locais. Para tal, os Estados Partes devem tomar medidas para facilitar o acesso físico e económico aos recursos produtivos, especialmente por parte das mulheres rurais, e para, de um modo geral, assegurar as necessidades nutricionais particulares de todas as mulheres sob a sua jurisdição (COMITÊ PARA A ELIMINAÇÃO DA DISCRIMINAÇÃO CONTRA MULHERES, 1999, grifo nosso).

No Brasil, corroborando com a ideia de que a equidade de gênero é importante para a promoção e garantia do DHAA o Decreto $n^{\circ} 7.272 / 2010$ - que regulamenta a Losan - estabeleceu como um dos objetivos da Política Nacional de Segurança Alimentar e Nutricional - PNSAN:

Art. $4^{\circ}$ Constituem objetivos específicos da PNSAN:

II - articular programas e ações de diversos setores que respeitem, protejam, promovam e provejam o direito humano à alimentação adequada, observando as diversidades social, cultural, ambiental, étnicoracial, a equidade de gênero e a orientação sexual, bem como disponibilizar instrumentos para sua exigibilidade (BRASIL, 2010, grifo nosso);

O decreto também prevê que o Plano Nacional de Segurança Alimentar e Nutricional deve observar as demandas das populações com atenção para as especificidades dos grupos populacionais em situação de vulnerabilidade e insegurança alimentar e nutricional, respeitando a equidade de gênero (artigo 19, V) e que o sistema de monitoramento e avaliação da PNSAN deve identificar os grupos populacionais mais vulneráveis à violação do DHAA, consolidando dados sobre desigualdades de gênero (artigo 21, § 6º (BRASIL, 2010).

A Lei ${ }^{\circ} 11.326 / 2006$ também aborda o tema e estabelece como princípio da Política Nacional da Agricultura Familiar e Empreendimentos Familiares Rurais a equidade na aplicação das políticas e respeitos aos aspectos de gênero ${ }^{9}$ (BRASIL, 2006).

\footnotetext{
9 “Art. $4^{\circ}$ A Política Nacional da Agricultura Familiar e Empreendimentos Familiares Rurais observará, dentre outros, os seguintes princípios:
} 
A Política Nacional de Agroecologia e Produção Orgânica - PNAPO (Decreto $n^{\circ}$ 7.794/2012) traz como diretriz a redução das desigualdades de gênero, por meio de programas e ações que promovam a autonomia econômica das mulheres ${ }^{10}$.

Com o intuito de garantir o DHAA de mulheres e adolescentes em privação de liberdade, em especial gestantes, lactantes e com filhos e filhas, a Resolução n ${ }^{\circ} 9$ do Conselho Nacional dos Direitos Humanos dispôs que a privação de sua liberdade fere o DHAA e que a imposição de fome e sede as mulheres e adolescentes em privação de liberdade é considerada tortura. Além disso, prevê diversas garantias na impossibilidade de aplicação de medidas alternativas à privação de liberdade (BRASIL, 2017):

Art. $2^{\circ}$ - Na impossibilidade de aplicação de medidas alternativas à privação de liberdade de mulheres e adolescentes gestantes, lactantes e com filhos e filhas, o Estado deverá garantir:

I - A promoção da alimentação adequada e saudável às mulheres, adolescentes e seus filhos e filhas, por meio de 5 (cinco) refeições em horários regulares, compreendendo o uso de alimentos in natura e minimamente processados, variados, seguros, que respeitem a cultura, as tradições e os hábitos alimentares saudáveis, contribuindo para a manutenção da saúde, em conformidade com a faixa etária, inclusive dos que necessitam de atenção nutricional específica;

II - Um aporte adicional de energia proveniente da alimentação de $300 \mathrm{Kcal} / \mathrm{dia}$ para o segundo e terceiro trimestre de gestação às mulheres e adolescentes gestantes;

III - O fornecimento de uma alimentação adequada e saudável para a lactante, para viabilizar a adequada produção do leite materno, em quantidade e qualidade suficientes para atender às suas necessidades nutricionais e às do seu bebê, com aporte adicional de energia proveniente da alimentação de $500 \mathrm{Kcal} / \mathrm{dia}$;

IV - A oferta de refeições planejadas para cobrir o total das necessidades nutricionais diárias dos indivíduos e grupos atendidos, contando com nutricionistas nas unidades de produção direta e nos serviços terceirizados para oferta de refeições nas instituições prisionais;

$\mathrm{V}$ - A oferta de água potável e própria para o consumo, sob livre demanda;

VI - A consulta à mulher e à adolescente sobre o interesse em amamentar e/ou alimentar seu filho e filha, respeitando a opção da mãe e, havendo o seu interesse, garantir orientação e apoio para o aleitamento materno e alimentação adequada; VII - Atenção especial ao direito das mulheres e adolescentes vivendo com HIV ou AIDS de alimentar seus filhos e filhas, garantindo o vínculo e respeito à alimentação adequada;

VIII - O direito à amamentação por livre demanda, sem restrição de tempo de amamentação, em local apropriado;

IX - A criação de condições e ambientes que permitam às mulheres e adolescentes alimentar e/ou amamentar seus filhos e filhas;

$\mathrm{X}$ - Oferta de alimentos adequados e saudáveis para as crianças menores de 2 anos, respeitando as quantidades, a qualidade e a consistência conforme diretrizes e princípios estabelecidos no Guia Alimentar para Crianças Menores de 2 anos, do Ministério da Saúde;

III - eqüidade na aplicação das políticas, respeitando os aspectos de gênero, geração e etnia;” (BRASIL, 2006).

10 “Art. $3^{\circ}$ São diretrizes da PNAPO:

VII - contribuição na redução das desigualdades de gênero, por meio de ações e programas que promovam a autonomia econômica das mulheres” (BRASIL, 2012). 
XI - Tratamento médico e psicológico em caso de abortos, espontâneos ou não; XII - A não utilização de algema durante os atos médico-hospitalares preparatórios para a realização do parto, durante o trabalho de parto e pós-parto; XIII - O direito de mulheres e adolescentes migrantes internacionais de convivência familiar com seus filhos e filhas, em condições adequadas e com tratamento humanitário e digno, garantindo-se atenção integral à saúde, comunicação com a família, oportunidade de trabalho, estudo e esporte, meios para remessa do dinheiro aos seus familiares, intérprete para solicitar esclarecimentos e receber informações processuais, cursos de português, livre manifestação religiosa, concessão benefícios de progressão de regime, liberdade condicional e de responder ao processo em liberdade, indulto e direito de permanência no Brasil após o nascimento de seus filhos e filhas;

XIV - A regulação da oferta e comercialização de alimentos nas unidades prisionais, devendo ser evitados alimentos ultraprocessados (BRASIL, 2017).

As desigualdades de gênero ainda não superadas são fatores que influenciam diretamente na insegurança alimentar e nutricional de pessoas, famílias, comunidades. O reconhecimento destas desigualdades pode ser o primeiro passo para mudanças e novas frentes de ação para sua superação.

Devido à indivisibilidade e interdependência dos direitos humanos, torna-se necessário enxergar a promoção dos direitos humanos das mulheres e seu empoderamento como elementos primordiais para a efetivação do DHAA das mulheres e dos que estão ao seu redor.

\section{Dimensão Cultural}

Embora o acesso ao alimento em quantidade e qualidade seja imprescindível para a manutenção da vida, o universo do DHAA não se restringe a isso. Como característica dos direitos humanos ${ }^{11}$, ele possui também uma dimensão cultural.

Assim, tratar sobre a alimentação é, diretamente, tratar sobre cultura. Desde o plantio até o preparo e consumo do alimento existem aspectos culturais que precisam ser observados, respeitados e valorizados.

O Comentário Geral $n^{\circ} 12$ para o DHAA, por exemplo, explica que o conceito de adequação está condicionado às condições culturais e que a aceitabilidade de acordo com cada cultura faz parte do conteúdo essencial do DHAA (ONU, 1999).

No âmbito da legislação brasileira, é possível observar que ao longo do texto da Losan a cultura aparece como componente do DHAA:

Art. $2^{\circ} \mathrm{A}$ alimentação adequada é direito fundamental do ser humano, inerente à dignidade da pessoa humana e indispensável à realização dos direitos

\footnotetext{
${ }^{11}$ Segundo Meyer-Bisch (2008, p. 30): “a dimensão cultural de cada direito humano não é um relativismo, e isso não é só uma simples melhoria, mas uma condição de adequação do objeto do direito às capacidades do sujeito em aceder aos recursos culturais apropriados (alimentação, moradia e também justiça adequadas). Trata-se, portanto, de uma condição da efetividade para cada direito humano".
} 
consagrados na Constituição Federal, devendo o poder público adotar as políticas e ações que se façam necessárias para promover e garantir a segurança alimentar e nutricional da população.

$\S 1^{\circ}$ A adoção dessas políticas e ações deverá levar em conta as dimensões ambientais, culturais, econômicas, regionais e sociais;

Art. $3^{\circ}$ A segurança alimentar e nutricional consiste na realização do direito de todos ao acesso regular e permanente a alimentos de qualidade, em quantidade suficiente, sem comprometer o acesso a outras necessidades essenciais, tendo como base práticas alimentares promotoras de saúde que respeitem a diversidade cultural e que sejam ambiental, cultural, econômica e socialmente sustentáveis.

Art. $4^{\circ}$ A segurança alimentar e nutricional abrange:

V - a garantia da qualidade biológica, sanitária, nutricional e tecnológica dos alimentos, bem como seu aproveitamento, estimulando práticas alimentares e estilos de vida saudáveis que respeitem a diversidade étnica e racial e cultural da população;

VI - a implementação de políticas públicas e estratégias sustentáveis e participativas de produção, comercialização e consumo de alimentos, respeitando-se as múltiplas características culturais do País (BRASIL, 2006, grifo nosso).

O reconhecimento do aspecto cultural da alimentação como dimensão do DHAA protege e valoriza as multiformas culturais enraizadas na alimentação em todos os seus aspectos, seja desde os modos de cultivo até as formas de consumo do alimento.

Nesse sentido, de acordo com Siqueira (2015, p. 1 e 2) "a alimentação não deve ser compreendida como mero ato de comer, mas também como um ato social e um ato cultural singularmente humanos, com rituais próprios de cada grupo, ligando-se ao contexto coletivo em que se insere".

Segundo Lima; Neto; Farias (2015, p. 512) a transformação do alimento em comida é um processo cultural:

A natureza produz os alimentos, mas a cultura faz surgir códigos importantes, como por exemplo, as diferentes opções de cardápios, as receitas, os hábitos, que por sua vez, se relacionam ao paladar, ao prazer relacionado às propriedades organolépticas dos alimentos e, sobretudo, ao prazer da degustação.

Desse modo, quando se compreende que a alimentação culturalmente adequada é um direito, se fortalece a luta para que ela não seja considerada apenas como monopólio e regalia de poucos. Por isso, o estudo e validação dessa dimensão cultural são essenciais para a realização plena do DHAA:

$\mathrm{O}$ ato de comer e de nutrir-se é muito mais que um ato instintivo movido pela sensação de fome. Seres humanos não se alimentam com ferro, proteínas e vitaminas. Nós nos alimentamos com refeições, que são socialmente produzidas desde o momento de semeadura e colheita de culturas alimentares diversificadas, até o momento do preparo e da partilha. Seres humanos, ao longo de sua evolução, desenvolveram uma relação complexa com o processo alimentar, transformando- 
o em um ritual rico de criatividade, partilha, amor, solidariedade e comunhão entre seres humanos e com a natureza, permeado pelas características culturais de cada comunidade e agrupamento humano (VALENTE, 2019, p. 98).

Alimento carrega afeto, costumes, simbologias e tradições, desde o preparo como é feito que vão do uso dos equipamentos e uso práticas alimentares modernas, mas também da manutenção e coexistência de práticas culturalmente tradicionais (fogão à lenha, panela de barro, com colher de pau, ingredientes) ao modo que é servido (na folha de bananeira, na panela, em uma porcelana) e consumido (em pé, sentados à mesa, com as mãos, na frente da TV ou usando o computador ou smartphone).

A cultura está diretamente relacionada às práticas alimentares de determinado grupo de pessoas. Um alimento que pode ser habitual para determinado grupo, pode ser considerado exótico para outro (LIMA, 2015). Assim, quando se fala em DHAA fala-se em respeito às diversidades culturais, tradições populares e religiosas de cada povo.

Siqueira (2013) traz o exemplo do respeito aos presidiários que não consomem carne de porco, por questões religiosas. Bessa (2019) aborda o direito ao fornecimento de opções vegetarianas em escolas e o fornecimento de alimentos/receitas tradicionais a pessoas indígenas ou de comunidades locais.

Outro exemplo de seria a cesta básica que, enquanto para uns é base da alimentação diária, para outros, destoa de seus padrões culturais, como no caso de muitos indígenas, e outros povos tradicionais.

Dessa forma, quando se fala em dimensão cultural do DHAA, fala-se em um alimento culturalmente adequado, seja no cultivo, preparo ou consumo. Em outras palavras, ao longo de todo sistema alimentar a dimensão cultural precisa ser observada, reforçando assim o que ensina Roberto Da Matta: “Comida não é apenas uma substância alimentar, mas é também um modo, um estilo e um jeito de alimentar-se" (p. 56).

Promover a dimensão cultural do DHAA no cultivo do alimento significa respeitar Soberania Alimentar e Nutricional do agricultor e de toda comunidade. É permitir que os sistemas e saberes locais permaneçam. É garantir o uso de sementes crioulas. É garantir o acesso à terra, como no caso de povos indígenas, quilombolas, e outros grupos tradicionais, de modo que eles tenham área suficiente para praticar a reprodução socioeconômica e cultural.

Promover a dimensão cultural do DHAA no consumo é proporcionar condições para que os cidadãos escolham um alimento adequado a sua cultura, que o preparem e o consumam de acordo com seus costumes. 
No contexto Brasileiro, abordar a dimensão cultural do DHAA é refletir sobre as inúmeras possibilidades, haja vista que o país é multicultural (SIQUEIRA, 2013). Alimentos e receitas regionais, festas, usos e costumes, fazem parte da identidade cultural do país e englobam o DHAA.

O barreado do Paraná. O acarajé da Bahia. O tutu de feijão de Minas Gerais. O pato no tucupi do Pará. O cuscuz paulista. São apenas alguns exemplos de preparações que contêm uma grande riqueza no que se refere ao patrimônio cultural e regional.

Nesse sentido, os artigos 215 e 216 da Constituição federal dispõem sobre a garantia aos direitos culturais e fontes da cultura nacional e reconhecem como patrimônio cultural brasileiro tanto os bens materiais quanto imateriais, nos quais o texto constitucional inclui: as formas de expressão, os modos de criar, fazer e viver, as criações científicas, artísticas e tecnológicas, entre outros (BRASIL, 1988).

No contexto da alimentação, visando a patrimonialização de bens culturais imateriais ${ }^{12} 13$, o Instituto do Patrimônio Histórico e Artístico Nacional - Iphan, com base no Decreto $n^{\circ}$ 3.551/2000, registrou o Sistema Agrícola Tradicional das Comunidades Quilombolas do Vale do Ribeira; o Modo Artesanal de Fazer Queijo de Minas, nas regiões do Serro, da Serra da Canastra e do Salitre, em Minas Gerais; o Sistema Agrícola Tradicional o Rio Negro; a Produção Tradicional e Práticas Socioculturais Associadas à Cajuína no Piauí; o Ofício das Baianas de Acarajé; as Tradições Doceiras da Região de Pelotas e Antiga Pelotas (BRASIL, 2000; IPHAN, 2014c).

Tal patrimonialização reafirma o aspecto cultural da alimentação e contribui para a preservação de hábitos alimentares tradicionais. Um exemplo seria o das práticas socioculturais associadas à cajuína, que ocorreu em 2014. Característica do Piauí, tal bebida é produzida de modo artesanal, local e vinculada à cultura piauiense. O pedido foi realizado pela Cooperativa de Produtores de Cajuína do Piauí - CAJUESP para preservar a participação da agricultura familiar na produção da bebida que estava ameaçada por uma grande multinacional (Coca Cola) que pretendia fabricá-la em larga escala sob o nome de "Crush Cajuína” (SANTILLI, 2015).

\footnotetext{
12 Quanto aos bens imaterias, segundo o artigo $2^{\circ}$ da Convenção para a Salvaguada do Patrimônio Cultural Imaterial (UNESCO, 2014): Entende-se por "patrimônio cultural imaterial" as práticas, representações, expressões, conhecimentos e técnicas - junto com os instrumentos, objetos, artefatos e lugares culturais que lhes são associados que as comunidades, os grupos e, em alguns casos, os indivíduos reconhecem como parte integrante de seu patrimônio cultural. Este patrimônio cultural imaterial, que se transmite de geração em geração, é constantemente recriado pelas comunidades e grupos em função de seu ambiente, de sua interação com a natureza e de sua história, gerando um sentimento de identidade e continuidade e contribuindo assim para promover o respeito à diversidade cultural e à criatividade humana. [...].

${ }^{13}$ Segundo Santilli (2015) o entendimento do Iphan é que o instrumento de registro não destina a receitas de comidas, mas aos rituais, práticas e significados a elas vinculados.
} 
A valorização cultural dos alimentos e toda sua diversidade é um elemento de resistência à homogeneização ou padronização alimentar. Nesse contexto, ressalta-se que a homogeneização alimentar, segundo Lima; Neto; Farias (2015, p. 519), tende a ocorrer ao "igualar os comedores dos tempos pós-modernos que, sob a influência da globalização, passariam rapidamente a ter hábitos e gostos alimentares muito semelhantes". Tal padronização tem como causa, além do processo de globalização alimentar, também a produção industrial de alimentos facilmente acessível à maior parte da população, inclusive os de baixa renda e em vulnerabilidade social, por ter maior durabilidade de armazenamento do que os alimentos in natura, o que para muitas famílias pode representar uma considerável importância na relação custo-benefício, além da quantidade de açúcar, gordura e sal contido na maior parte desses alimentos que interferem no sabor. Neste sentido, o fator cultural perde em centralidade na escolha alimentar. Muito embora não se pode perder de vista a resistência cultural dos alimentos, haja vista que muitas famílias de pequenos agricultores, agroecológicos e grupos tradicionais seguem lutando pela valorização da produção artesanal e tradicional dos alimentos e ofertando-os em feiras, mercados e outras formas de redes curtas de comercialização.

Importante esclarecer que a globalização e a industrialização da produção e consumo de alimentos, em si, não são um problema, mas se tornam quando se sobrepõem aos hábitos locais por interesses puramente econômicos e de pressão por assimilação de práticas alimentares de outros países. O enfoque cultural da alimentação dentro das peculiaridades de cada comunidade contém história, identidade, valores e tradições incalculáveis e não podem ser atropelados por aspectos meramente econômicos.

\section{Dimensão Informação}

O conhecimento e a segurança na escolha dos alimentos são essenciais para a realização do DHAA. Para isso, o acesso à informação é primordial. O consumidor tem o direito de saber em que consiste uma alimentação adequada e também tem o direito de compreender o que está comendo, sem manipulações, distorções ou omissões.

A Losan relaciona a produção de conhecimento e o acesso à informação à Segurança Alimentar e Nutricional:

Art. $4^{\circ}$ A segurança alimentar e nutricional abrange:

III - a promoção da saúde, da nutrição e da alimentação da população, incluindose grupos populacionais específicos e populações em situação de vulnerabilidade social;

IV - a garantia da qualidade biológica, sanitária, nutricional e tecnológica dos alimentos, bem como seu aproveitamento, estimulando práticas alimentares e estilos de vida saudáveis que respeitem a diversidade étnica e racial e cultural da população; 
V - a produção de conhecimento e o acesso à informação; (BRASIL, 2006, grifo nosso).

Saber de onde o alimento vem (origem), como é feito, quem o fez, são pressupostos para a realização do Direito Humano à Alimentação Adequada. Pode-se dizer que o direito à informação ${ }^{14}$ e o direito de livre escolha são premissas básicas do DHAA.

Porém, muitas podem ser as violações e este Direito. A globalização, a industrialização e a adição de novos componentes aos alimentos trazem preocupações para que o consumidor possa ter o conhecimento e informação como versa a Losan. Muitas vezes, as indústrias violam o DHAA na forma como conduzem suas publicidades e na forma como informam seus consumidores ${ }^{15}$ sobre seus produtos.

Quanto à publicidade de alimentos, a forma como ela é praticada é alvo de constantes questionamentos. Manipulações, distorções, informações inconsistentes, podem interferir diretamente nas escolhas das dietas das pessoas, levando-as a padrões alimentares não saudáveis.

Segundo Rundall (2015) existe um consenso que uma das maiores causas dos problemas de obesidade está diretamente relacionada ao marketing de alimentos altamente processados (com elevados níveis de sal, açúcar e/ou gordura).

A publicidade direcionada a crianças ${ }^{16}$ também é elencada como fator que contribui para obesidade entre crianças e adolescentes. Em estudo realizado por Kelly et al (2010) foi demonstrado conexões diretas entre escolhas, compras e consumo alimentares de crianças com publicidades televisivas de alimentos não saudáveis. Em estudo de caso realizado por Silva; Lima (2020), 65\% dos pais entrevistados admitiram que seus filhos sofrem influência da mídia no que tange ao comportamento alimentar e, $76 \%$ das crianças entrevistadas disseram realizar as refeições frequentemente sentadas assistindo televisão. Há nessa situação, a necessidade de informação aos pais sobre os riscos e influências a que estão sujeitos os filhos.

Segundo estudo realizado pelo Instituto Brasileiro de Defesa do Consumidor - IDEC e pelo Fundo das Nações Unidas para a Infância - UNICEF (2019) as estratégias de marketing e o grau de atratividade das embalagens possuem grande influência na decisão de compra e nas escolhas alimentares de crianças. Devido ao estágio de desenvolvimento emocional e cognitivo das

\footnotetext{
${ }^{14} \mathrm{O}$ Acesso à informação é um direito fundamental, assegurado pelo artigo $5^{\circ}$, XIV da Constituição Federal (BRASIL, 1988).

${ }^{15}$ Quando se fala em direito à informação e relações de consumo, o Código de Defesa do Consumidor também deve ser aplicado, o qual reconhece a vulnerabilidade do consumidor no mercado de consumo (BRASIL, 1990).

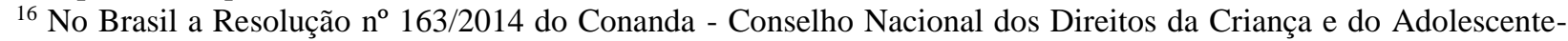
proíbe qualquer propaganda direcionada ao público infantil (CONANDA, 2014).
} 
crianças, elas acabam tendo seu direito de escolha limitado, em especial quando se deparam com propagandas abusivas.

A rotulagem de alimentos também é importante para que o consumidor possa fazer suas opções alimentares conscientemente. Todavia, a regulamentação clara e eficaz vive em constante embate com indústria alimentar. Em um momento no qual a diversidade de alimentos industrializados aumenta freneticamente, a rotulagem destes precisa ser clara e adequada; pois, a falta de conhecimento técnico para a leitura de rotulagens pode limitar a capacidade de escolha de quem consome alimentos industrializados.

Rotulagens específicas para informar a presença de transgênicos (Lei nº 11.105/2005, Portaria 2.658/2003), alimentos que contém lactose (ANVISA - Resolução Da Diretoria Colegiada

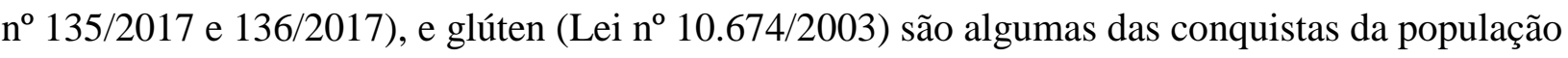
brasileira.

Outro tipo de rotulagem, ainda pouco discutido, é para identificar a presença de agrotóxicos nos alimentos. Embora existam determinações quanto a sua aplicação, ainda existem divergências se existe uma dose segura de agrotóxicos que podem ser ingeridas. Além disso, diversos estudos demonstram a presença em excesso desses componentes químicos nos alimentos.

Teixeira (2017) ao abordar sobre a presença de agrotóxicos nos alimentos ressalta que o consumidor ao não ter o acesso à informação da qualidade e origem dos alimentos tem sua liberdade e seu poder de escolha comprometidos. O autor defende que, independente de os agrotóxicos serem utilizados nas dosagens e períodos corretos, eles precisam ser informados ao consumidor:

[...] a relação consumerista deve ser transparente e harmônica, ou seja, ao consumidor deve se informar quais agrotóxicos foram utilizados na produção e qual o período das respectivas aplicações. Dessa forma, o consumidor pode escolher livremente se adquire e consume tais produtos (TEIXEIRA, 2017, p. 145).

Cabe ressaltar que o consumidor não tem a obrigação de ter o conhecimento técnico para entender as embalagens de produtos processados, muito pelo contrário a "cientifização" dos alimentos tem levado os consumidores a escolhas alimentares ruins, pela dificuldade em distinguir o que é realmente saudável ou não.

Pollan (2008) critica o nutricionismo - ideologia que parte da premissa que alimentos são a soma de seus nutrientes. Pois, as pessoas ficam reféns do que a "ciência" (muitas vezes tendenciosa aos interesses do mercado) diz ser um alimento saudável/nutritivo, pois nutrientes não são visíveis, e perdem a autonomia alimentar. 
O Guia Alimentar para a População Brasileira (BRASIL, 2014), elaborado em 2014, pode ser um exemplo de material que visa simplificar diretrizes alimentares. Ele tem como princípio a ampliação da autonomia nas escolhas alimentares e entende que o acesso a informações confiáveis contribui para isso. Além disso, ele classifica os alimentos em quatro categorias (alimentos in natura ou minimante processados, produtos extraídos de alimentos in natura, alimentos processados e alimentos ultraprocessados) e recomenda o consumo de alimentos in natura ou minimamente processados a alimentos ultraprocessados.

Por fim, destaca-se a importância da educação alimentar e nutricional como forma de capacitar cada cidadão, lhe dando poder e preparo para fazer boas escolhas alimentares. Normas que regulem as indústrias alimentícias são de extrema importância, mas a educação emancipadora pode ser a maior ferramenta de transformação e mudança de realidades.

\section{Dimensão Ambiental}

Não há como dissociar os direitos humanos - e, consequentemente o DHAA - da natureza e do direito ao ambiente ecologicamente equilibrado. Uma vida saudável depende de alimentos saudáveis e adequados, e estes, consequentemente, dependem de ecossistemas saudáveis. Nas palavras de Valente (2002, p. 105): “a alimentação humana é um complexo processo de transformação de natureza em gente, em seres humanos, ou seja, em humanidade".

A Losan relaciona a segurança alimentar com o ambiente:

Art. $4^{\circ}$ A segurança alimentar e nutricional abrange:

II - a conservação da biodiversidade e a utilização sustentável dos recursos (BRASIL, 2006);

Assim, o direito à alimentos ambientalmente sustentáveis faz parte do DHAA ${ }^{17}$. Ou seja, alimentos seguros e saudáveis, produzidos com respeito ao ambiente e os preservando para as gerações futuras. Valente (2002, p. 104) entende que:

Uma alimentação adequada é aquela que colabora para a construção de seres humanos saudáveis, conscientes de seus direitos e deveres, enquanto cidadãos do Brasil e do mundo. Conscientes, inclusive, de sua responsabilidade com o meio ambiente e com a qualidade de vida dos seus dependentes. Como já foi dito "Nós tomamos a emprestada de nossos descendentes, temos que ser capazes de devolvê-la como a recebemos, ou melhor".

A forma como a sociedade se desenvolveu e lida com a natureza tem gerado crises ambientais que afetam uma vida digna e a própria existência humana (SEUFERT, 2020).

\footnotetext{
17 O Comentário Geral no 12 faz referência a uma dimensão ambiental do DHAA, em especial nos pontos 4, 7 e 8
} (ONU, 1999). 
Além do cultivo dos alimentos, o processamento, a distribuição, o consumo e o descarte refletem na dimensão ambiental do DHAA. Seja nos tipos/quantidades/descartes de embalagens utilizadas, transporte e desperdício de alimentos.

Perda da biodiversidade, desmatamento, poluição, emissão de gases, aquecimento global, doenças, contaminação da água, solo e ar são resultados de sistemas alimentares insustentáveis.

Um exemplo seria o setor pecuário. De acordo com a FAO (2006) ele é fator chave no desmatamento e perda da biodiversidade. Também é responsável por $18 \%$ dos gases do efeito estufa (emissões medidas em CO2 equivalente), mais de $8 \%$ do uso global de água pelo homem e, possivelmente, o maior setor poluidor de água do mundo.

Tais resultados refletem diretamente na alimentação das pessoas, seja em dietas pouco diversificadas, na imposição de alimentos sem valor cultural, na contaminação de alimentos e da água, entre outros.

Além disso, esse modelo de produção, muitas vezes, prejudica aqueles que buscam sistemas alimentares sustentáveis, seja por meio da deriva de agrotóxicos ou contaminações transgênicas para outras propriedades, ou ainda, impedindo a pratica de modelos sustentáveis, como os de indígenas e povos tradicionais, ou ainda, impondo o uso de agrotóxicos e sementes transgênicas (CONSEA, 2012).

Além de práticas ambientalmente sustentáveis no âmbito da produção, processamento e distribuição de alimentos, cabe ressaltar que as escolhas do consumidor são importantes. Escolhas alimentares, também consideradas atos políticos, influenciam na manutenção de sistemas alimentares sustentáveis ou não.

Observa-se que as pessoas estão, a cada dia, mais desconectadas do que se alimentam. Não se sabe do que um alimento realmente é feito, sua origem.

Essa desconexão homem, alimento e natureza reflete diretamente nas violações do DHAA. Alimentos se tornaram mercadorias e pouco é informado quanto à procedência dos alimentos, impedindo, muitas vezes, o consumidor fazer escolhas mais sustentáveis.

A desconexão entre agricultor e consumidor, faz desaparecer a identidade do alimento, impossibilita àquele que consume entender toda a cadeia produtiva e resulta, muitas vezes, em uma desvalorização do que se come, e limita o consumidor a fazer suas escolhas baseadas pelo preço, calorias e nutrientes (POLLAN, 2013).

De Oliveira, Da Cruz e Schneider (2019) abordam a ideia de uma biografia ambiental dos alimentos. Ou seja, deve-se partir do pressuposto que os alimentos são iguarias produzidas em um ambiente e possuem significados ambientais desde sua produção até seu consumo. Cada alimento possui uma trajetória individual e as questões ambientais relacionam-se ao longo de toda a cadeia 
produtiva do alimento - lugar onde ele foi produzido, modo de produção, a forma/distância com transporte, embalagens. Todos esses fatores fazem parte da biografia alimento e precisam ser levados em consideração para que o consumidor faça uma escolha sustentável.

Porém, para isso é necessário que haja o fornecimento dessas informações. Tal ato depende da pressão dos consumidores, da responsabilidade daqueles que produzem o alimento e da regulação do Estado, para que haja consciência nas escolhas alimentares.

Assim, ao referirmos à alimentação adequada, não há como não incluir a dimensão ambiental. Os sistemas alimentares refletem diretamente na degradação do ambiente e prejudicam a vida na Terra das mais diversas formas. Dessa forma, a coexistência harmoniosa entre os seres humanos e natureza (afinal fazemos parte e dependemos dela) depende de escolhas alimentares sustentáveis.

A sustentabilidade precisa ser observada ao longo de todo o sistema alimentar e, para isso, interesses econômicos não podem prevalecer sobre as escolhas locais. A garantia da Soberania Alimentar dos povos é essencial. Assim, a conexão entre sistemas alimentares, sustentabilidade e Soberania Alimentar Nutricional para a promoção do DHAA é urgente.

\section{Considerações finais}

A riqueza do universo da alimentação reflete na riqueza do DHAA. Limitá-lo a questões nutricionais é sinônimo de violação não só dele, mas de diversos outros direitos.

A interdependência dos direitos humanos é nítida ao longo do aprofundamento dos estudos sobre o DHAA. Não há vida digna sem uma alimentação adequada, mas esta depende de acesso à informação, de condições financeiras para plantar ou adquirir alimentos, de equidade de gênero, de sistemas alimentares sustentáveis ambiental e cultural, acesso à terra e recursos produtivos e diversos outros aspectos.

Diante disso, foi possível constatar que é impossível minuciar todo conteúdo do DHAA. Porém, quanto mais se aprofunda em seu estudo, mas é possível tomar consciência da necessidade de exigi-lo e promovê-lo.

Agradecimento: À Coordenação de Aperfeiçoamento de Pessoal de Nível Superior pelo apoio com bolsa de pós-graduação nível mestrado. 


\section{Referências}

BELLOWS, Anne C.; LEMKE, Stefanie. The dimensions of gender and nutrition in the human right to adequate food. In: Food and nutrition security: towards the full realization of human rights. Policy in focus. Vol. 16. International Policy Centre for Inclusive Growth - United Nations Program: 2016. Disponível em: http://www.ipcundp.org/pub/eng/PIF36_Food_and_nutrition_security.pdf. Acesso em 01 dez. 2020.

BESSA, Adriana. 2019. The Normative Dimension of Food Sustainability: A Human RightsBased Approach to Food Systems Governance. Towards Food Sustainability Working Paper. n. 8. Bern, Switzerland: Centre for Development and Environment (CDE), University of Bern. Disponível em: https://www.cde.unibe.ch/unibe/portal/fak_naturwis/g_dept_kzen/b_cde/content/e65013/e54284 6/e542016/e810328/e810336/R4D_WP8_2019_eng.pdf. Acesso em: 12 nov 2020.

BOLD, Mara van Del; QUISUMBING, Agnes R.; GILLESPIE, Stuart. Women's Empowerment and Nutrition: an Evidence Review. IFPRI Discussion Paper 01294. International Food Policy Research Institute - $\quad$ IFPRI: 2013. Disponível em: http://ebrary.ifpri.org/utils/getfile/collection/p15738coll2/id/127840/filename/128051.pdf.

Acesso em: 25 nov. 2020.

BRASIL. Constituição da República Federativa do Brasil de 1988. Brasília, DF: Presidência da República, [2021]. Disponível em: http://www.planalto.gov.br/ccivil_03/constituicao/constituicao.htm. Acesso em: 17, fev. 2021.

BRASIL. Decreto $\mathbf{n}^{\circ}$ 3.551, de 04 de agosto de 2000. Institui o Registro de Bens Culturais de Natureza Imaterial que constituem patrimônio cultural brasileiro, cria o Programa Nacional do Patrimônio Imaterial e dá outras providências. Brasília: Presidência da República, [2021]. Disponível em: http://www.planalto.gov.br/ccivil_03/decreto/d3551.htm. Acesso em: 17 fev. 2021.

BRASIL. Decreto $\mathbf{n}^{\mathbf{0}}$ 7.272, de 25 de agosto de 2010. Regulamenta a Lei no 11.346, de 15 de setembro de 2006, que cria o Sistema Nacional de Segurança Alimentar e Nutricional - SISAN com vistas a assegurar o direito humano à alimentação adequada, institui a Política Nacional de Segurança Alimentar e Nutricional - PNSAN, estabelece os parâmetros para a elaboração do Plano Nacional de Segurança Alimentar e Nutricional, e dá outras providências. Brasília: Presidência da República, [2021]. Disponível em: https://www.planalto.gov.br/ccivil_03/_ato20072010/2010/decreto/d7272.htm. Acesso em: 27 jan. 2021.

BRASIL. Decreto no 7.794, de 20 de agosto de 2012. Institui a Política Nacional de Agroecologia e Produção Orgânica. Brasília: Presidência da República, [2021]. Disponível em: http://www.planalto.gov.br/ccivil_03/_ato2011-2014/2012/decreto/d7794.htm. Acesso em: 17 fev. 2021.

BRASIL. Decreto $\mathbf{N}^{0}$ 89.460, de 20 de março de 1984. Promulga a Convenção sobre a Eliminação de Todas as Formas de Discriminação contra a Mulher, 1979. Brasília: Presidência da República, [2020]. Disponível em: https://www2.camara.leg.br/legin/fed/decret/1980-1987/decreto-8946020-marco-1984-439601-publicacaooriginal-1-pe.html. Acesso em 09 dez. 2020.

BRASIL. Guia alimentar para a população brasileira. 2. ed. Brasília : Ministério da Saúde, 2014. Disponível em: http://www4.planalto.gov.br/consea/publicacoes/alimentacao-adequada-e- 
saudavel/guia-alimentar-para-a-populacao-brasileira-2014/8-guia-alimentar-para-a-populacaobrasileira-2014.pdf. Acesso em: 07 jul. 2020.

BRASIL. Lei no 8.078, de 11 de setembro de 1990. Dispõe sobre a proteção do consumidor e dá outras providências. Brasília, DF: Presidência da República, [2020]. Disponível em: http://www.planalto.gov.br/ccivil_03/leis/18078compilado.htm. Acesso em: 17 fev. 2020.

BRASIL. Lei $\mathbf{n}^{\mathbf{0}} \mathbf{1 0 . 6 7 4}$, de 16 de maio de 2003. Obriga a que os produtos alimentícios comercializados informem sobre a presença de glúten, como medida preventiva e de controle da doença celíaca. Brasília, DF: Presidência da República, [2020]. Disponível em: http://www.planalto.gov.br/ccivil_03/leis/2003/110.674.htm. Acesso em: 18 nov 2020.

BRASIL. Lei n⿳ 11.105, de 24 de março de 2005. Regulamenta os incisos II, IV e V do $\S 1^{\circ}$ do art. 225 da Constituição Federal, estabelece normas de segurança e mecanismos de fiscalização de atividades que envolvam organismos geneticamente modificados - OGM e seus derivados, cria o Conselho Nacional de Biossegurança - CNBS, reestrutura a Comissão Técnica Nacional de Biossegurança-CTNBio, dispõe sobre a Política Nacional de Biossegurança - PNB, revoga a Lei $\mathrm{n}^{\mathrm{o}}$ 8.974, de 5 de janeiro de 1995, e a Medida Provisória n $\mathrm{n}^{\circ} 2.191-9$, de 23 de agosto de 2001, e os arts. $5^{\circ}, 6^{\circ}, 7^{\circ}, 8^{\circ}, 9^{\circ}, 10$ e 16 da Lei $n^{\circ} 10.814$, de 15 de dezembro de 2003 , e dá outras providências. Brasília, DF: Presidência da República, [2021]. Disponível em: http://www.planalto.gov.br/ccivil_03/_ato2004-2006/2005/lei/111105.htm. Acesso em: 17 de fev. 2021.

BRASIL. Lei $\mathbf{n}^{\mathbf{0}}$ 11.326, de 24 de julho de 2006. Estabelece as diretrizes para a formulação da Política Nacional da Agricultura Familiar e Empreendimentos Familiares Rurais. Brasília, DF: Presidência da República, [2021]. Disponível em: http://www.planalto.gov.br/ccivil_03/_ato2004-2006/2006/lei/111326.htm. Acesso em: 17 de fev. 2021.

BRASIL. Lei $\mathbf{n}^{\mathbf{0}}$ 11.346, de 15 de setembro de 2006. Cria o Sistema Nacional de Segurança Alimentar e Nutricional - SISAN com vistas em assegurar o direito humano à alimentação adequada e dá outras providências. Brasília, DF: Presidência da República, [2020]. Disponível em: http://www.planalto.gov.br/ccivil_03/_Ato2004-2006/2006/Lei/L11346.htm. Acesso em 09 abr. 2020.

BRASIL. Ministério da Agricultura, Pecuária e Abastecimento. Portaria 2658, de 22 de dezembro de 2003. Definir o símbolo de que trata o art. $2^{\circ}, \S 1^{\circ}$, do Decreto 4.680, de 24 de abril de 2003, na forma do anexo à presente portaria. Brasília. DF: Ministério da Agricultura, Pecuária e Abastecimento, 2003. Disponível em: https://www.gov.br/agricultura/pt-br/assuntos/insumosagropecuarios/insumos-pecuarios/alimentacao-animal/arquivos-alimentacao-

animal/legislacao/portaria-no-2-658-de-22-de-dezembro-de-2003.pdf. Acesso em: 17 de fev. 2021.

BRASIL. Ministério da Mulher, da Família e dos Direitos Humanos. Conselho Nacional dos Direitos Humanos. Resolução n⿳ 9, de 06 de dezembro de 2017. Dispõe sobre o Direito Humano à Alimentação Adequada de mulheres e adolescentes em privação de liberdade, em especial gestantes, lactantes e com filhos e filhas. Brasília: MDH, 06 de dezembro de 2017. Disponível em: https://www.gov.br/mdh/pt-br/acesso-a-informacao/participacao-

social/old/cndh/resolucoes/copy_of_ResoluoCNDHn92017_DireitoHumanoAlimentaoAdequada demulhereseadolescentesemprivaodeliberdadeemespecialgestanteslactantesecomfilhosefilhas.pdf . Acesso em: 27 de jan. 2021. 
BRASIL. Ministério da Saúde. Agência Nacional De Vigilância Sanitária - ANVISA. Resolução - RDC No 135, de 8 de fevereiro de 2017. Altera a Portaria SVS/MS n ${ }^{\circ} 29$, de 13 de janeiro de 1998, que aprova o regulamento técnico referente a alimentos para fins especiais,para dispor sobre os alimentos para dietas com restrição de lactose. Diário Oficial da União: edição 29, seção 1, p. 44, 09 fev. 2017.

BRASIL. Ministério da Saúde. Agência Nacional De Vigilância Sanitária - ANVISA. Resolução - RDC No 136, de 8 de fevereiro de 2017. Estabelece os requisitos para declaração obrigatória da presença de lactose nos rótulos dos alimentos. Diário Oficial da União: edição 29, seção 1, p. 44, 09 fev. 2017.

BURITY, Valéria Torres Amaral. et al. Direito Humano à Alimentação Adequada no Contexto da Segurança Alimentar e Nutricional. Brasília, DF: ABRANDH, 2010. Disponível em: http://www.actuar-acd.org/uploads/5/6/8/7/5687387/dhaa_no_contexto_da_san.pdf. Acesso em: 17 set. 2017.

CAISAN - CÂMERA INTERMNISTERIAL DE SEGURANÇA ALIMENTAR E NUTRICIONAL. Mapeamento dos Desertos Alimentares no Brasil, Estudo Técnico. Secretaria-Executiva da Câmara Interministerial de Segurança Alimentar e Nutricional Ministério do Desenvolvimento Social/MDS, 2018.

CASTRO, Josué de. Geografia da Fome (o dilema brasileiro: pão ou aço). $10^{\text {a }}$ Ed. Rio de Janeiro: Antares Achiamé.1980.

COMITÊ PARA A ELIMINAÇÃO DA DISCRIMINAÇÃO CONTRA MULHERES. Recomendação Geral no 24: Artigo 12 da Convenção (mulheres e saúde). 1999. Disponível em: https://plataformamulheres.org.pt/projectos/cedaw4all/recomendacoes-gerais/. Acesso em: 09 dez. 2020.

COMMITTEE ON THE ELIMINATION OF DISCRIMINATION AGAINST WOMEN. General recommendation $n^{\mathbf{0}} 34$ on the rights of rural women. 2016. Disponível em: https://tbinternet.ohchr.org/Treaties/CEDAW/Shared\%20Documents/1_Global/INT_CEDAW_G EC_7933_E.pdf. Acesso em: 03 dez. 2020.

CONANDA - CONSELHO NACIONAL DOS DIREITOS DA CRIANÇA E DO ADOLECENTE. Resolução n⿳ 163, de 13 de março de 2014. Dispõe sobre a abusividade do direcionamento de publicidade e de comunicação mercadológica à criança e ao adolescente. Secretaria de Direitos Humanos, 2014. Disponível em: https://crianca.mppr.mp.br/arquivos/File/legis/conanda/resolucao_163_conanda.pdf. Acesso em: 17 fev. 2021.

CONSEA - CONSELHO NACIONAL DE SEGURANÇA ALIMENTAR E NUTRICIONAL. Os impactos dos agrotóxicos na Segurança Alimentar e Nutricional: Contribuições do Consea. CONSEA: 2012. Disponível em: http://antigo.contraosagrotoxicos.org/index.php/materiais/relatorios/os-impactos-dosagrotoxicos-na-seguranca-alimentar-e-nutricional-contribuicoes-doconsea/detail\#: :text=Os\%20impactos\%20dos\%20agrot $\% \mathrm{C} 3 \% \mathrm{~B} 3 \mathrm{xicos} \% 20 \mathrm{na} \% 20$ seguran $\% \mathrm{C} 3$ $\% \mathrm{~A} 7 \mathrm{a} \% 20$ alimentar\%20e\%20nutricional\%3A\%20contribui\%C3\%A7\%C3\%B5es\%20do\%20Co nsea,-

Tamanho\%3A\%202.7\%20MB\&text=O\%20Brasil\%2C\%20desde $\% 202008 \% 2 \mathrm{C} \% 20 \mathrm{mant} \% \mathrm{C} 3 \%$ 
A9m,\%C3\%A9\%20incompat\%C3\%ADvel\%20com\%20esse\%20quadro. Acesso em: 27 jan. 2021.

CORRÊA, Leonardo; OLIVEIRA, Lucas Costa. Direito Humano à Alimentação Adequada e a teoria crítica dos direitos humanos: um diálogo possível e necessário. In.: CORRÊA, Leonardo [org]; Diálogos sobre o Direito Humano à Alimentação Adequada. Juiz de Fora, MG: Faculdade de Direito da Universidade Federal de Juiz de Fora, 2019. Disponível em: https://actbr.org.br/uploads/arquivos/livro-dhaa-versc3a3o-final.pdf. Acesso em: 17 fev. 2021.

DaMATTA, Roberto da. O que faz o Brasil, Brasil? Rio de Janeiro: Rocco, 2001. 126 p.

DAUFENBACK, Vanessa; COELHO, Denise E. P.; BÓGUS, Cláudia M. Sistemas Alimentares e violações ao Direito Humano à Alimentação Adequada: reflexões sobre a pandemia de covid19 no Brasil. Segur.Aliment. Nutr., Campinas, v. 28, p. 1-13. e021005. 2021.

DE OLIVEIRA, Ana Luisa de Araujo; DA CRUZ, Fabiana Thomé; SCHNEIDER, Sergio. Sustentabilidade e escolhas alimentares: por uma biografia ambiental dos alimentos. Sustentabilidade em Debate, Brasília, v. 10, n. 1, p. 14-158, abr. 2019. Disponível em: https://periodicos.unb.br/index.php/sust/article/view/19280/21649. Acesso em: 31 ago. 2020.

DE SCHUTTER, Olivier. Report Submitted by the Special Rapporteur on the Right to Food: Women's rights and the right to food. Human Rigths Council Sixteenth Session. Agenda Item 3: Promotion and Protection of All Human Rights, Civil, Political, Economic, Social and Cultural Rights, Including the Right to Develop. United Nations (UN), 2012.

FAO. Diretrizes Voluntárias em Apoio à Realização Progressiva do Direito à Alimentação Adequada no Contexto da Segurança Alimentar Nacional. $127^{\mathrm{a}}$ Sessão do Conselho da FAO novembro de 2004. Roma, FAO: 2015. Disponível em: http://www.fao.org/3/y7937pt/Y7937PT.pdf. Acesso em: 04 dez. 2020.

FAO - Food and Agriculture Organization of the United Nations. Livestock's long shadow: environmental issues and options. FAO: 2006. Disponível em: http://www.fao.org/3/a0701e/a0701e00.htm. Acesso em: 01 fev. 2020.

FAO; IFAD; UNICEF; WFP; WHO. The State of Food Security and Nutrition in the World 2020. Transforming food systems for affordable healthy diets. Roma: FAO, 2020.

GUERRA, Sidney. Curso de Direitos Humanos. 6. ed. São Paulo: Saraiva Educação, 2020.

GRAZIANO DA SILVA, José. Agora, defender-se do vírus... E depois? Segur. Aliment. Nutr., Campinas, v. 27, p. 1-4. e020019. 2020. Disponível em: Vista do Agora, defender-se do vírus... E depois? (unicamp.br). Acesso em 02 mar. 2021.

IBGE. Pesquisa de orçamentos familiares 2017-2018: análise da segurança alimentar no Brasil. Rio de Janeiro : IBGE, 2020. Disponível em: https://biblioteca.ibge.gov.br/index.php/biblioteca-catalogo?view=detalhes\&id=2101749. Acesso em: 25 nov. 2020.

INSTITUTO BRASILEIRO DE DEFESA DO CONSUMIDOR - IDEC - Alimentando Políticas. Entre Desertos e Pântanos, quando a geografia urbana é um obstáculo para a alimentação saudável. 2019. Disponível em: https://alimentandopoliticas.org.br/wp- 
content/uploads/2019/05/idec-urban-food-sources-fact-sheet_a4-site.pdf. Acesso em: 20 nov. 2020 .

IDEC; UNICEF. Influência dos rótulos de alimentos ultraprocessados na percepção, preferências e escolhas alimentares de crianças brasileiras. São Paulo: IDEC; UNICEF, 2019. Disponível em: https://idec.org.br/sites/default/fi les/arquivos/pesquisa_idec_unicef_7.pdf. Acesso em: 19 jan. 2021.

INCA - INSTITUTO NACIONAL DE CÂNCER JOSÉ ALENCAR GOMES DA SILVA. Posicionamento do Instituto Nacional de Câncer José de Alencar Gomes da Silva acerca dos agrotóxicos. Abr. $2015 . \quad$ Disponível em: http://www1.inca.gov.br/inca/Arquivos/comunicacao/posicionamento_do_inca_sobre_os_agroto xicos_06_abr_15.pdf. Acesso em: 27 fev. 2018.

IPHAN. Livro de Registro os Saberes - Bens Culturais Imateriais. Iphan, c2014. Disponível em: http://portal.iphan.gov.br/pagina/detalhes/496. Acesso em: 12 jan. 2020.

KELLY, Bridget et al. Television food advertising to children: a global perspective. American journal of public health, v. 100, n. 9, p. 1730-1736, 2010. Disponível em: https://ajph.aphapublications.org/doi/full/10.2105/AJPH.2009.179267. Acesso em: 26 ago. 2020.

LIMA, Romilda de Souza; NETO, José A. F.; FARIAS, Rita de C. Pereira. Alimentação, comida e cultura: o exercício da comensalidade. Demetra; 2015; 10(3); 507-522.

LIMA, Romilda de Souza. Práticas alimentares e sociabilidades em famílias rurais da Zona da Mata mineira: mudanças e permanências. 2015. Tese (Doutorado em Extensão Rural) Universidade Federal de Viçosa, Viçosa, 2015.

MONTEIRO, Carlos Augusto. A dimensão da pobreza, da desnutrição e da fome no Brasil. Estudos avançados, v. 17, n. 48, p. 7-20, 2003. Disponível em: https://www.scielo.br/pdf/ea/v17n48/v17n48a02.pdf. Acesso em: 13 nov. 2020.

MANIGLIA, Elisabete. As interfaces do direito agrário e dos direitos humanos e a segurança alimentar [online]. São Paulo: Editora UNESP; São Paulo: Cultura Acadêmica, 2009. 277 p.

MEYER-BISCH, Patrice. A centralidade dos direitos culturais, pontos de contato entre diversidades e direitos humanos. Revista Observatório Itaú Cultural. v. 11, p. 25-42, 2008. Disponível em: http://d3nv1jy4u7zmsc.cloudfront.net/wp-content/uploads/2014/03/RevistaObservat\%C3\%B3rio-11.pdf. Acesso em: 13 jan. 2020.

ONU. Organização das Nações Unidas. Comitê de Direitos Econômicos, Sociais e Culturais do Alto Comissariado de Direitos Humanos/ONU. Comentário Geral número 12: O direito humano à alimentação (art.11). 1999. Disponível em: http://pfdc.pgr.mpf.mp.br/atuacao-econteudos-de-apoio/publicacoes/alimentacao-adequada/Comentario\%20Geral\%20No\%2012.pdf. Acesso em: 09 abr. 2020.

POLLAN, Michael. Em defesa da comida. Tradução: Adalgisa Campos da Silva. Rio de Janeiro: Editora Intrínseca Ltda, 2013. Título original: In Defense of Food. 
PRATLEY, Pierre. Associations between quantitative measures of women's empowerment and access to care and health status for mothers and their children: a systematic review of evidence from the developing world. Social Science \& Medicine, v. 169, p. 119-131, 2016.

RUNDALL, Patti. O "Negócio Da Má-Nutrição": O Encobrimento Perfeito Para As Grandes Empresas de Produtos Alimentares. In: Food First Information \& Action Network - FIAN Internacional et al. Observatório do Direito à Alimentação e à Nutrição - A nutrição dos povos não é um negócio. 7. ed. 2015. p. 24-28. Disponível em: https://www.righttofoodandnutrition.org/sites/www.righttofoodandnutrition.org/files/R_t_F_a_N _Watch_2015_port_single-page_Web.pdf. Acesso em: 18 nov. 2020.

SANTILLI, Juliana. O reconhecimento de comidas, saberes e práticas alimentares como patrimônio cultural imaterial. DEMETRA: Alimentação, Nutrição \& Saúde, v. 10, n. 3, p. 585 606, 2015. Disponível em: https://www.epublicacoes.uerj.br/index.php/demetra/article/view/16054. Acesso em: 12 jan. 2021.

SEUFERT, Philip. Nós somos a natureza! Direitos Humanos, direito ambiental e a ilusão da separação. In: Brot für die Welt; FIAN Internacional. Observatório do Direito à Alimentação e Nutrição. Uma reconexão com os alimentos a natureza e os direitos humanos para superar as crises ecológicas. 12. Ed. 2020. Disponível em: https://www.righttofoodandnutrition.org/files/rtfn_watch12-2020_por_0.pdf. Acesso em 10 dez. 2020.

SIQUEIRA, Dirceu Pereira. A dimensão cultural do direito fundamental à alimentação. 1. ed. Birigui, SP: Boreal Editora, 2013.

Teoria geral do direito à alimentação: cultura, cidadania e legitimação. 1. ed. Birigui, SP: Boreal Editora, 2015.

SILIPRANDI, Emma. Rural Brazilian Women and Food Acquisition Program. In: Brot für die Welt; FIAN International; ICCO Cooperation. Right to Food and Nutrition Watch. Alternatives and Resistance to Policies that Generate Hunger. 2013. p. 39-42. Disponível em: https://www.righttofoodandnutrition.org/alternatives-and-resistance-policies-generate-hunger.

Acesso em 01 dez. 2020.

SILVA, Lohana. L. M. da; LIMA, Romilda de S. A influência da mídia na formação do hábito alimentar infantil. In: BRASIL, C.C.B. Nutrição, Análise e Controle de Qualidade de Alimentos. Ponta Grossa: Atena. p. 34-44.

TEIXEIRA, Tarcisio Miguel. Saúde e direito à informação: o problema dos agrotóxicos nos alimentos. Revista de Direito Sanitário, v. 17, n. 3, p. 134-159, 2017.

UNESCO. Convenção para a Salvaguarda do Patrimônio Cultural Imaterial. Paris: UNESCO, 2003. Disponível em: https://ich.unesco.org/doc/src/00009-PT-Brazil-PDF.pdf. Acesso em 12 jan. 2021.

VALENTE, Flávio Luiz Schieck. Direito humano à alimentação: desafios e conquistas. São Paulo: Cortez, 2002.

VALENTE, Flávio Luiz Schieck. Fome, desnutrição e cidadania: inclusão social e direitos humanos. Saúde e sociedade, v. 12, n. 1, p. 51-60, 2003. 
VALENTE, Flávio Luiz Schiek. (2019). Rumo à realização plena do direito humano à alimentação e à nutrição adequadas. In: CORRÊA, Leonardo (org.). Diálogos sobre o Direito Humano à Alimentação Adequada. Juiz de Fora: Faculdade de Direito da Universidade Federal de Juiz de Fora, 2019. Disponível em: https://actbr.org.br/uploads/arquivos/livro-dhaa-versc3a3o-final.pdf. Acesso em 29 jun. 2020.

ZIEGLER, Jean. Destruição massiva, geopolítica da fome. Tradução: José Paulo Netto. São Paulo: Cortez Editora, 2012.

Recebido em: 18/09/2020 Aprovado em 27/01/2021 